\begin{tabular}{cc}
\hline International Journal of Engineering \& Technology, $7(2.6)(2018)$ 158-162 \\
SPC & Website: www.sciencepubco.com/index.php/IJET \\
Research Paper & Technology \\
\hline
\end{tabular}

\title{
A modified fuzzy approach to prioritize project activities
}

\author{
Sunny Joseph Kalayathankal ${ }^{1}$, Joseph Varghese Kureethara ${ }^{2 *}$, John T. Abraham ${ }^{3}$ \\ ${ }^{1}$ Research and Development Centre, Bharathiar University, Coimbatore, India \\ ${ }^{2}$ CHRIST (Deemed to be University), Bengaluru, India \\ ${ }^{3}$ Bharata Mata College, Kochi, India \\ *Corresponding author E-mail: frojoseph@christuniversity.in
}

\begin{abstract}
Project management is an important task in business although project is not just confined to business. Due to the uncertainty of the various variables involved in a project, over several past decades research is going on in the search for an efficient project management model. Although numerous crisp models are easily implementable, the potential of fuzzy models are huge. In the case of software development, the variables involved are highly dynamic. In this paper, we propose a ranking based fuzzy model that can prioritize various activities. We use a popular crisp model to test the effectiveness of the fuzzy model proposed. Simulation is done through Java Server Pages (JSP). There is considerable computational and managerial advantage in implementing the fuzzy model.
\end{abstract}

Keywords: Activity prioritizing; Fuzzy ranking; Project management; Fuzzyfication; Fuzzy soft sets.

\section{Introduction}

"A piece of planned work or an activity that is finished over a period of time and intended to achieve a particular purpose" is one of the meanings of the term project given by Cambridge Dictionary.[2] The three keywords associated with a project from this Cambridge meaning and definition are plan, purpose and finiteness of the time span between them. Both the plan and the purpose presuppose subjective elements in the project. They call the attention of someone who is behind the project. Then, the finitude of time points towards the urgency and limitedness of this someone to traverse from plan to purpose. That is to say, the limited time available has a huge impact on all types of projects. Every other resource can to a certain extent be replenished but not time. Together with time, every other limited resource has to be managed optimally to attain the expected result. Hence, we need to seriously munch over the managerial aspects of the project.

\section{Project Management}

The terms project and project management sometimes are used interchangeably. We, nevertheless, try to use the definition given by Kerzner for project management. It (Project Management) is the process of achieving the purpose of the project objectives by utilizing the existing organizational structures and resources in addition to applying a collection of tools and techniques.[14] Many authors and management gurus subscribe to the ideas contained in the above definition given by Kerzner. In terms of the utilization of the available organizational structures and resources, project managing team or manager must have to sharpen the skills. In addition to that, constant updates regarding the tools and techniques will tell upon the efficiency of the execution of the project. Hence, according to Munns and Bjeirmi, a successful project management could certainly enhance the success of a project.[25]
When proceeding with the project, roadblocks are natural. The project manager/ management team must be vigilant and prudent in sensing them to ride over them or to bypass them. To face courageously and then to overcome many of the hurdles four factors are identified as critical. They are: (1) communication throughout the project, (2) clear objectives and scope, (3) breaking the project into 'bite-sized chunks' and (4) using project plans as working documents.[8] In this study, we focus on the third point. i. e., breaking the project into 'bite-sized chunks'.

The success of a project can simultaneously be viewed from the macro and microviewpoints. While the macro viewpoint takes care of the question "does the original concept tick?", the users and stakeholders are usually the ones looking at the latter viewpoint.[15, 16] The micro viewpoint usually has serious concerns as it is more complex and intractable. In this viewpoint, the project is approached, assessed and understood in 'bite-sized chunks'.

\section{Software Development as a Project}

There are numerous types of projects. Any classification of projects into categories will invite criticisms. A major reason behind this is the subjective nature of projects due to dynamic environments they are rooted in. In spite of this, there are some certain attempts to classify projects based on various approaches. Youker identifies projects as nine different families. They are Administrative, Construction, Computer Software Development, Design of Plans, Equipment or System Installation, Event or Relocation, Maintenance of Process Industries, New Product Development and Research. Our focus in this work is on Computer Software Development Project.[27]

Software development is unique in comparison with other types of projects. It is more an intellectual project than physical. Brain functioning, logical skills, personal dispositions, interpersonal relationship etc. are vital in any software development project. Owing to these and other subjective factors involved, the predictability of completion and success of the project is very difficult. 
Insofar as we know, the role of leadership is critical in software development projects. All the more important is that of each and every programmer in the project. Level of perfection vis a vis quality is another very important variable associated with the software development project. As in any project, software development projects require motivating factors from a strong project leadership that can lead to knowledge sharing, team development and innovation. [1]

\section{Critical Issues in Project}

There are several critical issues that cannot be left unattended for a successful project completion. An elaborative list of critical factors for successful implementation of any project is given by Terry Cooke-Davies.[10, 23] They are: (1) adequacy of company-wide education on the concepts of risk management, (2) maturity of an organisation's processes for assigning ownership of risks, (3) adequacy with which a visible risk register is maintained, (4) adequacy of an up-to-date risk management plan, (5) adequacy of documentation of organisational responsibilities on the project, (6) shorter duration, (7) allowing changes to scope only through a mature scope change control process, (8) maintaining the integrity of the performance measurement baseline, (9) the existence of an effective benefits delivery and management process that involves the mutual cooperation of project management and line management functions, (10) portfolio- and programme management practices that allow the enterprise to resource fully a suite of projects that are thoughtfully and dynamically matched to the corporate strategy and business objectives, (11) a suite of project, programme and portfolio metrics that provides direct "line of sight" feedback on current project performance, and (12) anticipated future success, so that project, portfolio and corporate decisions can be aligned and finally an effective means of "learning from experience" on projects, that combines explicit knowledge with tacit knowledge in a way that encourages people to learn and to embed that learning into continuous improvement of project management processes and practices.[10]

\section{Some Popular Project Management Tech- niques}

Critical Path Method (CPM) and Programme Evaluation Review Technique (PERT) are the two most famous project management techniques to plan, schedule and control complex projects.[9, 15 22] During the last six decades of their existence, they have been highly effective in all types of projects. Multiple-Criteria Decision Analysis (MCDA) is another method is systematically dealing with project management.[4-6, 11] Although part of MCDA, the ELimination and Choice Expressing REality (ELiminationEtChoixTraduisant la REalité in French) (ELECTRE) is another famous project management tool. The Preference Ranking Organization METHod for Enrichment of Evaluations (PROMETHEE) is yet another project management method hailing from the family of MCDA.[18] All these methods or techniques are useful in micro-level project management.

In all the methods mentioned above and in most of the other project management techniques at least in a veiled manner ranking concepts are used. Mota et al. proposed a multiple criteria decision model for assigning priorities to activities in project management.[20] It is a novel ranking method. We apply a fuzzy approach to prioritise the events in a software development project with the analogous activities in the Electrical Substation Construction studied by Mota et al. In proposing so, we bring out better project output in terms of finance, personnel, equipment, space, time etc.

There are eight activities or project characteristics that are considered in this work considered in work: (1) Average duration of every activity, (2) Total number of predecessors, (3) Work experience, (4) Quality of the staff, (5) Total cost, (6) Resource mobili- zation, (7) Impact on commissioning and (8) Slack time of the activities. Note that work experience refers to either the experience before the actual activity or the set of information available at the time of activity. Highly qualified technical staff in different areas are needed to be involved. Unavailability of them will certainly harm the project. A major requirement is the total cost for conducting the project. Resource mobilization is a very tough job in the project environment. Every activity depends of the instant availability of the resources required for it. Problems can erupt at any level of the project. Most crucial problems that can seriously impact the project are the problems associated with the commission of the project.

Real world problems are generally categorized into two, viz., White Box problems and Black Box problems. The White Box problems are those that can be understood clearly and are well defined. These problems are also known as glass box problems or clear box problems due to the nature of the problems. On the contrary, Black Box problems are vaguely understood and are not well defined. Fuzzy type problems deal with Black Box problems as they are mostly vague, unclear, imprecise, inexact and/or inefficient. They deal with insufficient information too. In this article we develop a fuzzy based model to predicting project activities.

\section{Model Construction}

Every real time problem can be converted in to a Mathematical model. The real time parameters are always crisp in nature and have some uncertainty exists. The information available may not be correct and unconditional. For example, medium humidity, excellent capacity, heavy voltage, low memory cannot be recorded as crisp. We can easily classify the real time problem in to the class of low, medium, high, very high etc., and assign fuzzy value to each classification. This is done by the help of triangular or trapezoidal membership functions.[7]

Over the last few decades, fuzzy logic (FL) has been increasingly used in computer modeling. The fuzzy computing model involves several processes such as (1) Identifying the parameters, (2) Estimating the parameters from crisp data to fuzzy values, (3) Computing the fuzzy values using some mathematical formulas or algorithms, (4) Interpreting the result using fuzzy values, (5) or transferring the fuzzy value to crisp data and predict the result using this data. In 1965, Zadeh [29] initiated these types of studies. Fuzzy set theory has so many applications in Pure and Applied Mathematics. It has so many applications in engineering and technology, database management system, artificial intelligence, project design and evaluation system management, phycology, dynamical systems and in many other applied sciences. A fuzzy set can be defined as an extension of classical set theory by assigning a value for an individual in the universe between two boundaries that is represented by a membership function. The membership function for a set $\mathrm{A}$ denoted by $\mu_{\mathrm{A}}$, is defined as $\mu_{\mathrm{A}}: \mathrm{X} \rightarrow[0,1]$ where $[0,1]$ denotes the interval of real numbers from 0 to 1 , inclusive.

We cannot successfully use the traditional classical methods because of various types of uncertainties are present in these problems. Molodtsov [19] initiated the concept of soft set (SS) theory as a new mathematical tool for dealing with uncertainties which are free from the above difficulties. Let $\mathrm{U}$ be a universal set and $\mathrm{E}$ be a set of parameters (real-valued variables). Let $\mathrm{P}(\mathrm{U})$ denote the power set of $U$ and let $A$ be a subset of $U$. A pair $(F, A)$ is called a soft set over $\mathrm{U}$, where $\mathrm{F}$ is a mapping given by $\mathrm{F}: \mathrm{A} \rightarrow \mathrm{P}(\mathrm{U})$.

A lot of uncertainties exist in soft set theory. This is mainly because, this theory applied in practical problems that deals with two state devices only; i. e., all the elements in fuzzy soft set (FSS) theory contains 0 and 1 only. It is the major drawback of the soft set theory it deals with two extremes only. To avoid these problems Maji et al.[17] introduced the concept called fuzzy soft set theory which also deals with uncertainties. In fuzzy soft set theory, $\mathrm{P}(\mathrm{U})$ denotes the set of all fuzzy sets of $\mathrm{U}$. 
Example. Let $\mathrm{S}_{1}, \mathrm{~S}_{2}, \mathrm{~S}_{3}, \mathrm{~S}_{4}$ and $\mathrm{S}_{5}$ be project activities and $\mathrm{P}_{1}, \mathrm{P}_{2}$, $\mathrm{P}_{3}$ and $\mathrm{P}_{4}$ be the parameters. Then $\mathrm{F}\left(\mathrm{P}_{1}\right)=\left\{\mathrm{S}_{1}, \mathrm{~S}_{2}, \mathrm{~S}_{4}\right\}, \mathrm{F}\left(\mathrm{P}_{2}\right)=\left\{\mathrm{S}_{2}\right.$, $\left.\mathrm{S}_{5}\right\}, \mathrm{F}\left(\mathrm{P}_{3}\right)=\left\{\mathrm{S}_{1}, \mathrm{~S}_{2}, \mathrm{~S}_{3}\right\}$ and $\mathrm{F}\left(\mathrm{P}_{4}\right)=\left\{\mathrm{S}_{2}, \mathrm{~S}_{3}, \mathrm{~S}_{5}\right\}$. Each approximation has two parts, viz., a predicate and an output set. See Table 1. Suppose, $\mathrm{F}\left(\mathrm{P}_{1}\right)=\left\{\mathrm{S}_{1} / 0.9, \mathrm{~S}_{2} / 0.45, \mathrm{~S}_{3} / 0.85, \mathrm{~S}_{4} / 0.32, \mathrm{~S}_{5} / 0.85\right\}$, $\mathrm{F}\left(\mathrm{P}_{2}\right)=\left\{\mathrm{S}_{1} / 0.13, \mathrm{~S}_{2} / 0.8, \mathrm{~S}_{3} / 0.14, \mathrm{~S}_{4} / 0.15, \mathrm{~S}_{5} / 0.95\right\}$, $\mathrm{F}\left(\mathrm{P}_{3}\right)=\left\{\mathrm{S}_{1} / 0.15, \mathrm{~S}_{2} / 1.0, \mathrm{~S}_{3} / 0.29, \mathrm{~S}_{4} / 0.75, \mathrm{~S}_{5} / 0.74\right\}$ and $\mathrm{F}\left(\mathrm{P}_{4}\right)=\left\{\mathrm{S}_{1} / 0.87, \mathrm{~S}_{2} / 0.23, \mathrm{~S}_{3} / 0.89, \mathrm{~S}_{4} / 0.92, \mathrm{~S}_{5} / 0.36\right\}$. See the output in Table 2.

Table 1: Example of a Soft Set

\begin{tabular}{|l|l|l|l|l|}
\hline $\mathrm{U}$ & $\mathrm{P}_{1}$ & $\mathrm{P}_{2}$ & $\mathrm{P}_{3}$ & $\mathrm{P}_{4}$ \\
\hline $\mathrm{S}_{1}$ & 1 & 0 & 1 & 0 \\
\hline $\mathrm{S}_{2}$ & 1 & 1 & 1 & 1 \\
\hline $\mathrm{S}_{3}$ & 0 & 0 & 1 & 1 \\
\hline $\mathrm{S}_{4}$ & 1 & 0 & 0 & 0 \\
\hline $\mathrm{S}_{5}$ & 0 & 1 & 0 & 1 \\
\hline
\end{tabular}

Table 2: Example of a Fuzzy Soft Set

\begin{tabular}{|c|c|c|c|c|}
\hline $\mathrm{C}$ & $\mathrm{P}_{1}$ & $\mathrm{P}_{2}$ & $\mathrm{P}_{3}$ & $\mathrm{P}_{4}$ \\
\hline $\mathrm{S}_{1}$ & 0.9 & 0.13 & 0.15 & 0.87 \\
\hline $\mathrm{S}_{2}$ & 0.45 & 0.8 & 1 & 0.23 \\
\hline $\mathrm{S}_{3}$ & 0.85 & 0.14 & 0.29 & 0.89 \\
\hline $\mathrm{S}_{4}$ & 0.32 & 0.15 & 0.75 & 0.92 \\
\hline $\mathrm{S}_{5}$ & 0.85 & 0.95 & 0.74 & 0.36 \\
\hline
\end{tabular}

We define now E-bank, Activity factor (AF), Param factor (PF) and Efficiency indicator (EI). An E- bank is a square table (matrix) of activity variables $A_{i}$. Each entry $l_{i j}$ is the number of attributes for which the membership grade of $\mathrm{A}_{i}$ exceeds or equals the membership grade of $A_{j}, 0 \leq 1_{i j} \leq n$, where $n$ is the number of parameters. Each main diagonal element of an E- bank is always equal to the constant $n$, where $n$ is the number of parameters of the system. The Activity factor is denoted by $\mathrm{AF}_{\mathrm{ri}}$ and is defined as $\mathrm{AF}_{\mathrm{ri}}=\sum_{j=1}^{n}$ lij. The Param factor is denoted by $\mathrm{PF}_{\mathrm{j}}$ and is defined as $\mathrm{PF}_{\mathrm{j}}=\sum_{i=1}^{n}$ lij. The efficiency indicator discriminates the ranking project activities, and is given $\mathrm{EI}_{\mathrm{i}}=\mathrm{AF}_{\mathrm{ri}}-\mathrm{PF}_{\mathrm{j}}$.

\subsection{Optimization Algorithm}

1. Identifying the project activities (m).

2. Identifying the number of parameters (n).

3. Developing FSS (F, E).

4. Formation of E- bank.

5. Computation of Activity factor, Param factor.

6. Computation of efficiency indicator.

7. Construction of $\mathrm{AF}_{\mathrm{ri}}$ and $\mathrm{PF}_{\mathrm{i}}$ optimization table.

8. Ordering the project activities from $\mathrm{AF}_{\mathrm{ri}}$ and $\mathrm{PF}_{\mathrm{i}}$ optimization table

\section{Experiment and Result}

In the present work, all the activity characteristics are defined as crisp values. The parameter cost of the project can not affect the fuzzy ranking process. So cost is considered as a normalizing factor. But the number of working days can be considered as part of the equivalent cost. The crisp values can be converted into fuzzy membership grading using fuzzyfication. The reverse process is called de-fuzzyfication. It is very complicated to determine the membership function of the fuzzy variables even when the membership functions of the variables of crisp values are given. The first step of the proposed model is the conversion of crisp data to fuzzy grading. It is calculated by using the ratio of the actual entry to maximum value of the corresponding column. i. e., each entry is divided by its maximum value. This value always lies between 0 and 1 . When we divide maximum by maximum, we get the maximum fuzzy grade 1 . The project activities are denoted by $\mathrm{A}_{\mathrm{i}}$ for $\mathrm{i}=1$ to 32.[20] The parameters or characteristics viz., Code, Activity Name, Average Length (Days), Predecessor, Experience, Staff, Mobilizing Resources, Impact on commissioning and Slack times (days) are respectively denoted by $\mathrm{P}_{1}, \mathrm{P}_{2}, \mathrm{P}_{3}, \mathrm{P}_{4}, \mathrm{P}_{5}, \mathrm{P}_{6}$ and
$\mathrm{P}_{7}$. The crisp data of Electric Substation Construction Project (ESCP) are collected from Motaet al.

Table 3: Fuzzy Soft Set of ESCP Project Activities

\begin{tabular}{|l|l|l|l|l|l|l|l|}
\hline Code $(\mathrm{C})$ & $\mathrm{P}_{1}$ & $\mathrm{P}_{2}$ & $\mathrm{P}_{3}$ & $\mathrm{P}_{4}$ & $\mathrm{P}_{5}$ & $\mathrm{P}_{6}$ & $\mathrm{P}_{7}$ \\
\hline $\mathrm{A}_{1}$ & - & - & - & - & - & - & - \\
\hline $\mathrm{A}_{2}$ & - & - & - & - & - & - & - \\
\hline $\mathrm{A}_{3}$ & 0.7394 & 0.25 & 0.33 & 0.11 & 0.33 & 0.11 & 1 \\
\hline $\mathrm{A}_{4}$ & 0.7387 & 0.25 & 0.77 & 0.55 & 0.33 & 0.11 & 0 \\
\hline $\mathrm{A}_{5}$ & 0.5479 & 0.25 & 0.55 & 1 & 0.11 & 0.11 & 0 \\
\hline $\mathrm{A}_{6}$ & 0.2809 & 0.25 & 0.33 & 0.33 & 0.33 & 0.11 & 0.7378 \\
\hline $\mathrm{A}_{7}$ & 0.7665 & 0.25 & 0.33 & 1 & 0.33 & 0.77 & 0.0309 \\
\hline $\mathrm{A}_{8}$ & 0.6835 & 0.50 & 0.33 & 1 & 0.33 & 0.11 & 0.1175 \\
\hline $\mathrm{A}_{9}$ & 0.7394 & 0.50 & 0.33 & 1 & 0.33 & 0.77 & 0.0652 \\
\hline $\mathrm{A}_{10}$ & 1 & 0.25 & 0.55 & 1 & 0.55 & 1 & 0 \\
\hline $\mathrm{A}_{11}$ & 0.2605 & 1 & 0.33 & 1 & 0.33 & 0.77 & 0 \\
\hline $\mathrm{A}_{12}$ & - & - & - & - & - & - & - \\
\hline $\mathrm{A}_{13}$ & 1 & 0.25 & 0.77 & 0.11 & 0.77 & 0.55 & 0 \\
\hline $\mathrm{A}_{14}$ & 0.9595 & 0.25 & 1 & 0.55 & 0.11 & 0.11 & 0.0378 \\
\hline $\mathrm{A}_{15}$ & 0.9588 & 0.25 & 0.55 & 0.55 & 0.77 & 0.11 & 0.0385 \\
\hline $\mathrm{A}_{16}$ & - & - & - & - & - & - & - \\
\hline $\mathrm{A}_{17}$ & 0.7123 & 0.50 & 0.33 & 0.55 & 0.33 & 0.11 & 0 \\
\hline $\mathrm{A}_{18}$ & 0.4929 & 0.50 & 0.11 & 1 & 0.77 & 0.33 & 0.2052 \\
\hline $\mathrm{A}_{19}$ & - & - & - & - & - & - & - \\
\hline $\mathrm{A}_{20}$ & 0.5070 & 0.25 & 0.33 & 0.77 & 0.33 & 0.11 & 0 \\
\hline $\mathrm{A}_{21}$ & 0.5612 & 0.25 & 0.33 & 0.77 & 0.33 & 0.11 & 0 \\
\hline $\mathrm{A}_{22}$ & 1 & 0.25 & 0.55 & 0.55 & 0.11 & 0.11 & 0.5508 \\
\hline $\mathrm{A}_{23}$ & 0.9497 & 0.25 & 0.33 & 1 & 0.11 & 0.33 & 0 \\
\hline $\mathrm{A}_{24}$ & 0.5612 & 0.75 & 0.33 & 1 & 0.77 & 1 & 0.4335 \\
\hline $\mathrm{A}_{25}$ & 0.6433 & 0.75 & 0.77 & 1 & 1 & 1 & 0 \\
\hline $\mathrm{A}_{26}$ & 0.4256 & 0.50 & 0.55 & 0.77 & 0.33 & 0.33 & 0.6130 \\
\hline $\mathrm{A}_{27}$ & - & - & - & - & - & - & - \\
\hline $\mathrm{A}_{28}$ & 0.0778 & 0.25 & 0.11 & 0.55 & 0.11 & 0.11 & 0 \\
\hline $\mathrm{A}_{29}$ & 0.1355 & 0.50 & 0.11 & 0.77 & 0.33 & 0.11 & 0 \\
\hline $\mathrm{A}_{30}$ & 0.1764 & 0.25 & 0.11 & 1 & 0.77 & 0.11 & 0.0345 \\
\hline $\mathrm{A}_{31}$ & 0.1067 & 0.50 & 0.11 & 1 & 0.77 & 0.11 & 0 \\
\hline $\mathrm{A}_{32}$ & - & - & - & - & - & - & - \\
\hline & & & & & & & \\
\hline
\end{tabular}

Table 4: Ranking (R) table for Project Activities

\begin{tabular}{|c|l|l|l|l|l|}
\hline $\mathrm{C}$ & Activities & $\mathrm{AF}$ & $\mathrm{PF}$ & $\mathrm{EI}$ & $\mathrm{R}$ \\
\hline $\mathrm{A}_{1}$ & Start & & & & \\
\hline $\mathrm{A}_{2}$ & Substation Project & & & & \\
\hline $\mathrm{A}_{3}$ & Purchase report & 108 & 125 & -17 & 13 \\
\hline $\mathrm{A}_{4}$ & Choice of Site & 109 & 131 & -22 & 14 \\
\hline $\mathrm{A}_{5}$ & Basic Project & 104 & 137 & -33 & 17 \\
\hline $\mathrm{A}_{6}$ & Acquisition of the site & 96 & 135 & -39 & 18 \\
\hline $\mathrm{A}_{7}$ & Executive Project telecommunications & 128 & 102 & 26 & 6 \\
\hline $\mathrm{A}_{8}$ & Executive Project civil & 128 & 106 & 22 & 7 \\
\hline $\mathrm{A}_{9}$ & Executive Project Electromechanical & 138 & 85 & 53 & 4 \\
\hline $\mathrm{A}_{10}$ & Executive Project MPCC & 142 & 85 & 57 & 3 \\
\hline $\mathrm{A}_{11}$ & Specification of Service contract & 123 & 105 & 18 & 9 \\
\hline $\mathrm{A}_{12}$ & Supplying the substation & - & - & - & - \\
\hline $\mathrm{A}_{13}$ & Acquisition of components & 122 & 96 & 26 & 6 \\
\hline $\mathrm{A}_{14}$ & Formalizing acquisition of site & 107 & 112 & -5 & 11 \\
\hline $\mathrm{A}_{15}$ & Contracting construction & 122 & 102 & 20 & 8 \\
\hline $\mathrm{A}_{16}$ & Construction of the substation & - & - & - & - \\
\hline $\mathrm{A}_{17}$ & Earth Work & 107 & 133 & -26 & 16 \\
\hline $\mathrm{A}_{18}$ & Installing the ground grid & 122 & 88 & 34 & 5 \\
\hline $\mathrm{A}_{19}$ & Milestone earthwork & - & - & - & - \\
\hline $\mathrm{A}_{20}$ & Bases & 98 & 148 & -50 & 20 \\
\hline $\mathrm{A}_{21}$ & Command Post & 101 & 146 & -45 & 19 \\
\hline $\mathrm{A}_{22}$ & Access road & 112 & 113 & -1 & 10 \\
\hline $\mathrm{A}_{23}$ & Conduits & 112 & 123 & -11 & 12 \\
\hline $\mathrm{A}_{24}$ & Equipment & 147 & 65 & 82 & 2 \\
\hline $\mathrm{A}_{25}$ & Setting up MPCC & 149 & 61 & 88 & 1 \\
\hline $\mathrm{A}_{26}$ & Busbars & 121 & 87 & 34 & 5 \\
\hline $\mathrm{A}_{27}$ & Commissioning the substation & - & - & - & - \\
\hline $\mathrm{A}_{28}$ & Commissioning ground grid & 63 & 172 & -109 & 22 \\
\hline $\mathrm{A}_{29}$ & Commissioning equipment & 88 & 144 & -56 & 21 \\
\hline $\mathrm{A}_{30}$ & Commissioning the MPCC & 103 & 127 & -24 & 15 \\
\hline $\mathrm{A}_{31}$ & Final Commissioning & 106 & 128 & -22 & 14 \\
\hline $\mathrm{A}_{32}$ & End & - & - & - & - \\
\hline & & & & \\
\hline
\end{tabular}

The proposed model is applied to the fuzzy grading in Table 3. The E-bank is computed in Table 5 and activity factor, param 


\begin{tabular}{|c|c|c|c|c|c|c|c|c|c|c|c|c|c|c|c|c|c|c|c|c|c|c|c|c|c|}
\hline \multicolumn{26}{|c|}{ Table 5: E Bank } \\
\hline $\mathrm{C}$ & $\mathrm{A}_{3}$ & $\mathrm{~A}_{4}$ & $\mathrm{~A}_{5}$ & $\mathrm{~A}_{6}$ & $\mathrm{~A}_{7}$ & $\mathrm{~A}_{8}$ & $\mathrm{~A}_{9}$ & $\mathrm{~A}_{10}$ & $\mathrm{~A}_{11}$ & $\mathrm{~A}_{13}$ & $\mathrm{~A}_{14}$ & $\mathrm{~A}_{15}$ & $\mathrm{~A}_{17}$ & $\mathrm{~A}_{18}$ & $\mathrm{~A}_{20}$ & $\mathrm{~A}_{21}$ & $\mathrm{~A}_{22}$ & $\mathrm{~A}_{23}$ & $\mathrm{~A}_{24}$ & $\mathrm{~A}_{25}$ & $\mathrm{~A}_{26}$ & $\mathrm{~A}_{28}$ & $\mathrm{~A}_{29}$ & $\mathrm{~A}_{30}$ & $\mathrm{~A}_{31}$ \\
\hline $\mathrm{A}_{3}$ & 7 & 5 & 5 & 6 & 4 & 5 & 4 & 2 & 4 & 3 & 4 & 3 & 5 & 3 & 6 & 6 & 4 & 4 & 3 & 2 & 3 & 6 & 5 & 5 & 4 \\
\hline $\mathrm{A}_{4}$ & 5 & 7 & 6 & 6 & 3 & 4 & 2 & 3 & 4 & 4 & 4 & 4 & 6 & 2 & 6 & 6 & 5 & 4 & 2 & 3 & 3 & 7 & 5 & 4 & 4 \\
\hline $\mathrm{A}_{5}$ & 4 & 4 & 7 & 5 & 3 & 3 & 2 & 4 & 4 & 3 & 4 & 4 & 4 & 3 & 6 & 5 & 5 & 5 & 2 & 2 & 3 & 7 & 5 & 5 & 5 \\
\hline $\mathrm{A}_{6}$ & 5 & 4 & 4 & 7 & 4 & 4 & 3 & 2 & 4 & 3 & 4 & 3 & 4 & 2 & 5 & 5 & 4 & 4 & 2 & 1 & 2 & 6 & 5 & 5 & 4 \\
\hline $\mathrm{A}_{7}$ & 6 & 6 & 6 & 6 & 7 & 5 & 5 & 3 & 6 & 4 & 4 & 3 & 6 & 4 & 7 & 7 & 4 & 6 & 3 & 3 & 4 & 7 & 6 & 5 & 5 \\
\hline $\mathrm{A}_{8}$ & 5 & 5 & 6 & 6 & 5 & 7 & 5 & 3 & 5 & 3 & 5 & 4 & 6 & 4 & 7 & 7 & 4 & 5 & 3 & 3 & 4 & 7 & 7 & 6 & 6 \\
\hline $\mathrm{A}_{9}$ & 6 & 6 & 6 & 6 & 6 & 6 & 7 & 3 & 6 & 4 & 5 & 4 & 7 & 5 & 7 & 7 & 4 & 6 & 3 & 3 & 5 & 7 & 7 & 6 & 6 \\
\hline $\mathrm{A}_{10}$ & 6 & 6 & 7 & 6 & 6 & 5 & 5 & 7 & 6 & 5 & 5 & 5 & 6 & 4 & 7 & 7 & 6 & 7 & 4 & 4 & 5 & 7 & 6 & 5 & 5 \\
\hline $\mathrm{A}_{11}$ & 5 & 5 & 5 & 5 & 5 & 5 & 5 & 3 & 7 & 4 & 4 & 3 & 6 & 4 & 6 & 6 & 4 & 6 & 3 & 3 & 4 & 7 & 7 & 5 & 6 \\
\hline $\mathrm{A}_{13}$ & 6 & 6 & 6 & 5 & 4 & 4 & 3 & 5 & 4 & 7 & 4 & 5 & 5 & 4 & 6 & 6 & 5 & 6 & 3 & 3 & 4 & 6 & 5 & 5 & 5 \\
\hline $\mathrm{A}_{14}$ & 5 & 6 & 6 & 5 & 4 & 3 & 2 & 3 & 3 & 4 & 7 & 5 & 5 & 2 & 5 & 5 & 5 & 5 & 2 & 3 & 2 & 7 & 4 & 5 & 4 \\
\hline $\mathrm{A}_{15}$ & 6 & 6 & 6 & 6 & 5 & 4 & 3 & 4 & 4 & 4 & 5 & 7 & 6 & 3 & 6 & 6 & 5 & 5 & 3 & 2 & 3 & 7 & 5 & 6 & 5 \\
\hline $\mathrm{A}_{17}$ & 5 & 5 & 5 & 6 & 3 & 5 & 3 & 2 & 4 & 3 & 4 & 3 & 7 & 3 & 6 & 6 & 4 & 4 & 2 & 2 & 3 & 7 & 6 & 4 & 5 \\
\hline $\mathrm{A}_{18}$ & 4 & 5 & 5 & 5 & 4 & 5 & 4 & 4 & 4 & 4 & 5 & 5 & 5 & 7 & 5 & 5 & 4 & 5 & 2 & 2 & 5 & 7 & 7 & 7 & 7 \\
\hline $\mathrm{A}_{20}$ & 5 & 5 & 4 & 6 & 3 & 3 & 2 & 2 & 4 & 3 & 4 & 3 & 5 & 2 & 7 & 6 & 4 & 4 & 1 & 1 & 3 & 7 & 6 & 4 & 4 \\
\hline $\mathrm{A}_{21}$ & 5 & 5 & 5 & 6 & 3 & 3 & 2 & 2 & 4 & 3 & 4 & 3 & 5 & 2 & 7 & 7 & 4 & 4 & 2 & 1 & 3 & 7 & 6 & 4 & 4 \\
\hline $\mathrm{A}_{22}$ & 5 & 5 & 6 & 5 & 4 & 4 & 3 & 4 & 3 & 4 & 6 & 6 & 5 & 3 & 5 & 5 & 7 & 5 & 3 & 2 & 2 & 7 & 4 & 5 & 4 \\
\hline $\mathrm{A}_{23}$ & 5 & 5 & 6 & 5 & 4 & 4 & 3 & 3 & 4 & 3 & 4 & 3 & 5 & 4 & 6 & 6 & 4 & 7 & 3 & 3 & 3 & 7 & 5 & 5 & 5 \\
\hline $\mathrm{A}_{24}$ & 5 & 5 & 6 & 6 & 6 & 6 & 6 & 5 & 6 & 5 & 5 & 5 & 6 & 7 & 7 & 7 & 4 & 6 & 7 & 4 & 5 & 7 & 7 & 7 & 7 \\
\hline $\mathrm{A}_{25}$ & 5 & 6 & 7 & 6 & 5 & 5 & 5 & 6 & 6 & 6 & 4 & 5 & 6 & 6 & 7 & 7 & 5 & 6 & 6 & 7 & 6 & 7 & 7 & 6 & 7 \\
\hline $\mathrm{A}_{26}$ & 5 & 5 & 5 & 6 & 4 & 5 & 4 & 3 & 4 & 3 & 5 & 5 & 6 & 4 & 6 & 6 & 6 & 5 & 2 & 1 & 7 & 7 & 7 & 5 & 5 \\
\hline $\mathrm{A}_{28}$ & 3 & 4 & 4 & 3 & 1 & 1 & 0 & 2 & 1 & 3 & 4 & 3 & 3 & 1 & 3 & 3 & 4 & 3 & 0 & 1 & 0 & 7 & 3 & 3 & 3 \\
\hline $\mathrm{A}_{29}$ & 4 & 5 & 4 & 4 & 2 & 3 & 2 & 2 & 2 & 3 & 4 & 3 & 5 & 2 & 5 & 5 & 4 & 3 & 0 & 1 & 3 & 7 & 7 & 3 & 5 \\
\hline $\mathrm{A}_{30}$ & 4 & 5 & 5 & 4 & 4 & 3 & 2 & 4 & 3 & 4 & 4 & 4 & 4 & 3 & 5 & 5 & 4 & 4 & 2 & 2 & 2 & 7 & 6 & 7 & 6 \\
\hline $\mathrm{A}_{31}$ & 4 & 5 & 5 & 4 & 3 & 4 & 3 & 4 & 3 & 4 & 4 & 4 & 5 & 4 & 5 & 5 & 4 & 4 & 2 & 2 & 3 & 7 & 6 & 5 & 7 \\
\hline
\end{tabular}

factors, and Ranking are obtained in Table 4. Any other fuzzy ranking methods can also be utilized; however, the selected ranking procedures have proven to be consistent with the literature and are easier to apply. $[9,12,13,21,26]$

Simulation has been described by Shannon as "the process of designing a computerized model of a system (or process) and conducting experiments with this model for the purpose either of understanding the behaviour of the system or of evaluating various strategies for the operation of the system".[24] It follows from this definition that we must concern ourselves with a precise formulation of the system to be studied, translation of this formulation into a computer program and interpretation and use of the simulation results. The software is built using Java server pages which runs in web-logic or Tomcat web server. Based on this information the implemented algorithm creates a possibility of predicting the ranking of activities and the input file read through JDBC ODBC connection.

\section{Conclusion}

This paper explores the ranking of using FSS to model project activities. There are a variety of uncertainties in project planning and ranking. Hence it is difficult to treat these uncertainties using traditional deterministic methods.[3] In this paper, we presented a simple and effective model to rank project activities. We illustrated our method through an example as well. The simulation done through Java Server Pages (JSP) shows that the two important activities are 'Setting up MPCC' and 'Equipment'. The output is compared with the results in the literature available in [20].

The advantages of this model are the simplicity of structure, easiness of comprehensibility, minimized computation time along with a non-complex computation method, high user friendliness and high throughput and accuracy. The added advantage of this model is that increase in parameter will not lead to increase in the complexity of the model. This shows that the number of parameters considered in this model cannot be considered to be exhaustive. A greater accuracy can certainly be achieved if the number of parameters is increased in a scientific manner.

In this model, we have used the membership grades of the parameters. There exists some uncertainty in the membership values. Hence, there is a possibility of experimenting with the nonmembership as well. In addition to that, using higher order fuzzy sets like Intuitionistic Fuzzy Sets by Atanassov and Ordered Intui- tionistic Fuzzy Sets by Kalayathankal may also be used. However, in that case the system becomes more complex and the computation becomes very tedious.

\section{Acknowledgement}

The authors wish to thank Mrs. Lizzamma Joseph, Officer, Life Insurance Corporation of India for her invaluable inputs on the ranking concepts.

\section{References}

[1] Anantatmula, V. S. (2010), "Project manager leadership role in improving project performance", Engineering Management Journal, 22(1), 13-22.

[2] Cambridge Advanced Learner's Dictionary, (2008).

[3] Chang, T. C. and Ibbs, C. W. (1990), "Priority ranking-A fuzzy expert system for priority decision making in building construction resource scheduling", Building and Environment, 25, 253267

[4] Chen, S. J. and Chen, S. M. (2003), “A new method for handling multicriteria fuzzy decision-making problems using FN-IOWA operators", Cybernetics and Systems: An International Journal, 34, 109-137.

[5] Chen, S. J. and Hwang, C. L. (1992), Fuzzy multiple attribute decision making methods and applications. Berlin, Germany: Springer-Verlag.

[6] Chen, Y. H. (1996), "Fuzzy ratings in mechanical engineering design-application to bearing selection", Proceedings of Institution of Mechanical Engineers, 210, 49-53.

[7] Chen, Y. H. (1997), "Determining parting direction based on minimum bounding box and fuzzy logic", International Journal of Machine Tools Manufacture, 37, 1189-1199.

[8] Clarke, A. (1999). A practical use of key success factors to improve the effectiveness of project management. International journal of project management, 17(3), 139-145.

[9] Cook, W. D. and Green, R. H. (2000), "Project prioritization: A resource-constrained data envelopment analysis approach", Socio-Economic Planning Sciences, 34, 85-99.

[10] Cooke-Davies, T. (2002), The "real" success factors on projects. International journal of project management, 20(3), 185190.

[11] Dias, L. C. and Moussea, V. (2003), "IRIS: A DSS for multiple criteria sorting problems", Journal of Multi-Criteria Decision Analysis 12, 285-298. 
[12] Green, R. H., Doyle, J. R. and Doyle, J. R. (1996), "Preference voting and project ranking using DEA and cross-evaluation", European Journal of Operational Research, 90, 461-472.

[13] Jha, K. N. and Misra, S. (2007), "Ranking and classification of construction coordination activities in Indian projects", Construction Management and Economics, 25, 409-421.

[14] Kerzner, H., \&Kerzner, H. R. (2017), Project management: a systems approach to planning, scheduling, and controlling. John Wiley \& Sons.

[15] Lam, E. W. M., Chan, A. P. C. and Chan, D. W. M. (2008), "Determinants of successful design-build projects", Journal of Construction Engineering and Management, 134, 333-341.

[16] Lim, C. S., \& Mohamed, M. Z. (1999), "Criteria of project success: an exploratory re-examination", International journal of project management, 17(4), 243-248.

[17] Maji, P.K. Biswas, R. A. and Roy, R. (2001), "Fuzzy Soft sets", The Journal of Fuzzy Mathematics, 9(3), 589-602.

[18] Mavrotas, G., Diakoulaki, D. and Caloghirou, Y. (2006), "Project prioritization under policy restrictions. A combination of MCDA with 0-1 programming", European Journal of Operational Research, 171, 296-308.

[19] Molodtsov, D. (1999), "Soft Set Theory-First Results", Computers and Mathematics with Applications, 37, 19 - 31.

[20] Mota, C. M. M., Almeida, A. T. and Alencar, L. H. (2009), "A multiple criteria decision model for assigning priorities to activities in project management", International Journal of Project Management, 27, 175-181.

[21] Oliveira, K. B., Oliveira, J. M. M. and Filho, R. H. Ranking projects using multivariate statistics. In Innovations and Advanced Techniques in Systems, Computing Sciences and Software Engineering, edited by K. Elleithy. Dordrecht, The Netherlands: Springer, (2008).

[22] Oral, M., Kettani, O., and Lang, P. (1991), "A methodology for collective evaluation and selection of industrial R\&D projects", Management Science, 37, 871-885.

[23] Pinto, J. K. and Slevin, D. P. (1987), "Critical factors in successful project implementation", IEEE transactions on engineering management, 1, 22-27.

[24] Sowlati, T., Paradi, J. C. and Suld, C. (2005), "Information systems project prioritization using data envelopment analysis", Mathematical and Computer Modelling, 41, 1279-1298.

[25] White, D. and Fortune, J. (2002), "Current practice in project management-An empirical study", International journal of project management, 20(1), 1-11.

[26] Yao, J. S. and Wu, K. (2000), "Ranking fuzzy numbers based on decomposition principle and signed distance", Fuzzy Sets and Systems, 116, 275-288.

[27] Youker, R. (1999, October). "The difference between different types of projects", In Proceedings of the 30th Annual Project Management Institute 1999 Seminars \& Symposium, Philadelphia, PA, USA.

[28] Zadeh, L. A. (1965), Information and control. Fuzzy sets, 8(3), 338-353. 